\title{
Prevalence and associated factors of HIV self-testing among men who have sex with men in Ningbo, China: a cross-sectional study
}

Hang Hong ${ }^{1}$, Hong-bo Shi ${ }^{1}$, Hai-bo Jiang ${ }^{1}$, Hong-jun Dong ${ }^{1 *}$ and Yun-liang Shen ${ }^{2^{*}}$

\begin{abstract}
Background: HIV testing and early linkage to care are critical for reducing the risk of HIV transmission. HIV self-testing (HIVST) is a useful tool for increasing HIV testing frequency.This study aimed to investigate HIVST rates among men who have sex with men (MSM), the characteristics of MSM who had HIVST, and factors associated with HIVST uptake among MSM in Ningbo, China.

Methods: A cross-sectional study was conducted from April to October 2019 in Ningbo,China. Participants were aged at least 18 years and having had sexual contact with men in the past year. Proportions were used for categorical variables. Adjusted Odds Ratio (AOR) and 95\% Confidence Interval (CI) for characteristics associated with HIVST uptake was processed by multivariable logistic regression models.

Results: Among a sample of 699 MSM recruited, 38.2\% had reported previous use of an HIV self-test kit. A greater proportion of HIVST users had a higher frequency of HIV testing ( $\geq 2$ times: $70.0 \%$ versus $41.2 \%, p<0.001$ ) in the past 1 year. The odds of older age (30-39 years: $\mathrm{AOR}=0.49, \mathrm{Cl} 0.32-0.76$; more than 40 years: $\mathrm{AOR}=0.07, \mathrm{Cl} 0.04-0.14$, compared to 18-29 years), bisexual ( $A O R=0.49, \mathrm{Cl} 0.29-0.84$ ) were lower among HIVST users, and were higher among MSM who were higher education level (high school: $\mathrm{AOR}=2.82, \mathrm{Cl} 1.70-4.69$, compared to middle school or less), gay apps use ( $A O R=1.86, \mathrm{Cl} 1.13-3.05)$, multiple male sex partners ( $\mathrm{OOR}=1.90, \mathrm{Cl} 1.29-2.80$ ), frequency of male-male sexual contact $\geq 1$ times per week ( $A O R=1.86, \mathrm{Cl} 1.30-2.66$ ), syphilis infection ( $A O R=5.48, \mathrm{Cl} 2.53-11.88$ ).
\end{abstract}

Conclusions: Further HIVST education should be strengthened for school-aged children and teenagers, and free HIVST kits may be provided to high-risk MSM through gay apps and CBO to achieve the increased HIV testing frequency.

Keywords: MSM, HIV self-testing, Gay apps, Associated factors, China

\section{Introduction}

Globally, there were an estimated 37.9 million people are living with HIV (PLWH), with about 1.7 million people newly infected with HIV at the end of 2018 [1]. Men who have sex with men (MSM) has become the high-risk

\footnotetext{
*Correspondence: donghj@nbcdc.org.cn; shenyl26@163.com

${ }^{1}$ Ningbo Municipal Center for Disease Control and Prevention, 237

Yongfeng Road, Ningbo 315010, Zhejiang, China

${ }^{2}$ Zhejiang Provincial Institute of Dermatology, 61 Wuyuan Road,

Deqing 313200, Zhejiang, China
}

group of HIV acquisition [2, 3]. MSM accounted for an estimated $17 \%$ of new HIV infections globally, including more than half of new HIV infections in western and central Europe and North America [4]. MSM was about 28 times more likely to be living with HIV than it was among all adult men in 2018 [5].

To end the AIDS epidemic by 2030, the "90-90-90" goal by 2020 set up by UNAIDS in 2014 (90\% of people with HIV infection diagnosed, $90 \%$ of people diagnosed on treatment, and $90 \%$ of people on treatment achieving virological suppression) [6]. However, it seems unlikely 
that many regions and countries would reach the target, especially the first 90\% [7]. In China, an estimated less than $70 \%$ of PLWH were aware of their HIV-positive status by the end of 2018 [8]. HIV testing and early linkage to care were critical for reducing the risk of viral transmission from infected persons However, key population groups including MSM were unwilling to seek voluntary HIV counseling and testing (VCT) in the hospital or Centers for Disease Control and Prevention (CDC) due to stigma and discrimination [9-11].

HIV self-testing (HIVST) had recommended being offered as an additional HIV testing approach by WHO in 2016 [12]. Testers take their blood sample to perform HIV rapid tests and interpret the result at the time and location of their choosing. Several studies showed that HIVST had generally high sensitivity and specificity and was an acceptable and feasible testing approach due to the convenience, privacy, and ease of use [13-15]. These characteristics make it a potentially useful tool for increasing testing frequency and easy to reach first time and repeat testers for HIV $[16,17]$. In China, HIVST is highly acceptable and easily available through drugstore, e-commerce platform and community-based organisations (CBO) [18].

Given the need to improve HIV testing rates and target the first of the United Nation's 90-90-90 HIV testing and treatment goals, the purpose of this study was to investigate HIVST uptake rates among MSM, the characteristics and factors associated with HIVST uptake among MSM in Ningbo, China.

\section{Methods}

\section{Study design and participants}

We conducted a cross-sectional survey from April 1 to October 30, 2019, in Ningbo. Ningbo is an eastern coastal city of China, nearby Shanghai, with an area of $9365 \mathrm{~km}^{2}$ and a population of approximately $8.54 \mathrm{mil}-$ lion people. HIV prevalence among MSM in Ningbo was $5.7 \%$ [19]. Convenience sampling of participants was recruited through a combined online and offline method. Flyer advertisements were posted in MSM venues (Three parks, two bars, and eight community events) and VCT clinic,as well as on gay websites and gay apps. The criteria for recruiting were (1) being male, (2) aged at least18 years, (3) having resided in Ningbo for at least 6 months, (4) having had sexual contact with men in the past year.

Interested MSM contacted trained project workers for assessment of eligibility. After providing written informed consent, eligible participants were asked to complete self-administered questionnaires. Project workers were instructed to check questionnaires in place to ensure collection of quality data.

\section{Questionnaire}

All data were collected through self-administered paper questionnaires by trained project workers. The following variables were included: (1) demographic information including age, marital status, education level, duration of local residence, monthly income, and sexual orientation; (2) gay apps (Blued, Jack'd, and ZANK) use including duration and frequency of apps use; (3) Sexual behaviors including role and frequency in sexual intercourse, multiple male sex partners, unprotected sex with men and syphilis infection in the past 6 months; (4) HIV testing including reasons for test, frequency of test, time since latest test and site of the latest test; (5) HIVST including self-reported used HIVST in the lifetime (HIVST users), the type of HIVST kit,way to receive HIVST kit.

\section{Statistical analysis}

Characteristics of all participants were described by categorical variables presented as absolute values and percentages. The demographic information, gay apps use, sexual behaviors and HIV testing compared between HIVST users and Non-HIVST users were examined by chi-square tests. Univariate and multivariable forward stepwise logistic regression models were performed to examine risk factors associated with HIVST. The statistical significance was defined as $\mathrm{P}<0.05$. All statistical analyses were performed in SPSS (version 21.0, IBM, Armonk, NY, USA).

\section{Ethical considerations}

This study protocol was reviewed and approved by the Institutional Review Board of the Ningbo CDC. Informed consent was asked to sign for all eligible participants when the survey was starting. Participants could receive a gift for prizes of up to 50 Chinese Yuan (CNY) upon the completion of the survey.

\section{Results \\ Participant characteristics}

Table 1 demonstrates the characteristics of the 699 MSM in Ningbo. The mean age was 31.9 (SD 8.8) years. Most participants $(81.1 \%)$ were less than 30 years, $63.4 \%$ were single, $70.4 \%$ had a high school education or above, $77.7 \%$ had lived in Ningbo for at least 2 years, $62.9 \%$ had an income above $5000 \mathrm{CNY}$ per month, and $74.8 \%$ self-identified as gay.

Most participants (83.4\%) had used gay apps in the past 6 months. Of the 583 gay app users, $85.8 \%(500 / 583)$ had used gay apps for at least 1 year, $56.9 \%(332 / 583)$ used them at least 5 times a day. In terms of sexual practice, half of the participants were engaged in both insertive anal intercourse and receptive anal intercourse equally. $46.1 \%$ had sex with men for at least once per week in the 
Table 1 Characteristics of study participants and of HIVST users and Non-HIVST users in Ningbo, China, 2019

\begin{tabular}{|c|c|c|c|c|}
\hline \multirow[t]{2}{*}{ Characteristics } & \multirow{2}{*}{$\begin{array}{l}\text { All participants } \\
\text { n (\%) }\end{array}$} & \multicolumn{3}{|c|}{ Subgroup comparison } \\
\hline & & $\begin{array}{l}\text { HIVST users } \\
\mathrm{n}(\%)\end{array}$ & $\begin{array}{l}\text { Non-HIVST users } \\
\text { n (\%) }\end{array}$ & P-value \\
\hline Overall & $699(100)$ & $267(100)$ & $432(100)$ & \\
\hline \multicolumn{5}{|l|}{ Demographics } \\
\hline \multicolumn{5}{|l|}{ Age (years) } \\
\hline $18 \sim$ & $330(47.2)$ & $155(58.1)$ & $175(40.5)$ & \multirow[t]{3}{*}{$<0.001$} \\
\hline $30 \sim$ & $237(33.9)$ & $92(34.5)$ & $145(33.6)$ & \\
\hline$\geq 40$ & $132(18.9)$ & $20(7.5)$ & $112(25.9)$ & \\
\hline \multicolumn{5}{|l|}{ Marital status } \\
\hline Single & $443(63.4)$ & $172(64.4)$ & $271(62.7)$ & \multirow[t]{2}{*}{0.653} \\
\hline Married & $256(36.6)$ & $95(35.6)$ & $161(37.3)$ & \\
\hline \multicolumn{5}{|l|}{ Education level } \\
\hline Middle school or less & $207(29.6)$ & $65(24.3)$ & $142(32.9)$ & \multirow[t]{3}{*}{0.022} \\
\hline High school & $264(37.8)$ & $101(37.8)$ & $163(37.7)$ & \\
\hline College or above & $228(32.6)$ & $101(37.8)$ & $127(29.4)$ & \\
\hline \multicolumn{5}{|l|}{ Duration of local residence (years) } \\
\hline$<2$ & $156(22.3)$ & $76(28.5)$ & $80(18.5)$ & \multirow[t]{2}{*}{0.002} \\
\hline$\geq 2$ & $543(77.7)$ & $191(71.5)$ & $352(81.5)$ & \\
\hline \multicolumn{5}{|l|}{ Monthly income (CNY) } \\
\hline$<5000$ & $259(37.1)$ & $74(27.7)$ & $185(42.8)$ & \multirow[t]{2}{*}{$<0.001$} \\
\hline$\geq 5000$ & $440(62.9)$ & $193(72.3)$ & $247(57.2)$ & \\
\hline \multicolumn{5}{|l|}{ Sexual orientation } \\
\hline Gay & $523(74.8)$ & $220(82.4)$ & $303(70.1)$ & \multirow[t]{3}{*}{0.001} \\
\hline Bisexual & $135(19.3)$ & $34(12.7)$ & $101(23.4)$ & \\
\hline Unknown/unsure & $41(5.9)$ & $13(4.9)$ & $28(6.5)$ & \\
\hline \multicolumn{5}{|l|}{ Gay apps usage } \\
\hline \multicolumn{5}{|l|}{ Gay apps use } \\
\hline Yes & $583(83.4)$ & $237(88.8)$ & $346(80.1)$ & \multirow[t]{2}{*}{0.003} \\
\hline No & $116(16.6)$ & $30(11.2)$ & $86(19.9)$ & \\
\hline \multicolumn{5}{|l|}{ Duration of gay apps use (years) } \\
\hline$<1$ & $83(14.2)$ & $25(10.5)$ & $58(16.8)$ & \multirow[t]{3}{*}{0.035} \\
\hline$\geq 1$ & $500(85.8)$ & $212(89.5)$ & $288(83.2)$ & \\
\hline Missing (No use of gay apps) & 116 & & & \\
\hline \multicolumn{5}{|c|}{ Frequency of gay apps use (times/day) } \\
\hline$<1$ & $66(11.3)$ & $22(9.3)$ & $44(12.7)$ & 0.036 \\
\hline $1-$ & $185(31.7)$ & $65(27.4)$ & $120(34.7)$ & \\
\hline$\geq 5$ & $332(56.9)$ & $150(63.3)$ & $182(52.6)$ & \\
\hline Missing (No use of gay apps) & 116 & & & \\
\hline Sexual behavior & & & & \\
\hline Role in sexual intercourse & & & & \\
\hline Insertive anal sex & $191(27.3)$ & $74(27.7)$ & $117(27.1)$ & 0.983 \\
\hline Receptive anal sex & $155(22.2)$ & $59(22.1)$ & $96(22.2)$ & \\
\hline Both & $353(50.5)$ & $134(50.2)$ & $219(50.5)$ & \\
\hline Frequency of male-male sexual & & & & \\
\hline$<1$ & $377(53.9)$ & $124(46.4)$ & $253(58.6)$ & 0.002 \\
\hline$\geq 1$ & $322(46.1)$ & $143(53.6)$ & $179(41.4)$ & \\
\hline Multiple male sex partners ${ }^{a}$ & & & & \\
\hline Yes & $196(28.0)$ & $87(32.6)$ & $109(25.2)$ & 0.035 \\
\hline No & $503(72.0)$ & $180(67.4)$ & $323(74.8)$ & \\
\hline
\end{tabular}


Table 1 (continued)

\begin{tabular}{|c|c|c|c|c|}
\hline \multirow[t]{2}{*}{ Characteristics } & \multirow{2}{*}{$\begin{array}{l}\text { All participants } \\
\mathrm{n}(\%)\end{array}$} & \multicolumn{3}{|c|}{ Subgroup comparison } \\
\hline & & $\begin{array}{l}\text { HIVST users } \\
\mathrm{n}(\%)\end{array}$ & $\begin{array}{l}\text { Non-HIVST users } \\
\text { n (\%) }\end{array}$ & P-value ${ }^{c}$ \\
\hline \multicolumn{5}{|l|}{ Unprotected sex with men ${ }^{\mathrm{a}}$} \\
\hline Yes & $190(27.2)$ & $64(24.0)$ & $126(29.2)$ & \multirow[t]{2}{*}{0.13} \\
\hline No & $509(72.8)$ & $203(76.0)$ & $306(70.8)$ & \\
\hline \multicolumn{5}{|l|}{ Syphilis Infection ${ }^{b}$} \\
\hline Yes & $44(6.3)$ & $29(10.9)$ & $15(3.5)$ & \multirow[t]{2}{*}{$<0.001$} \\
\hline No & $655(93.7)$ & $238(89.1)$ & $417(96.5)$ & \\
\hline \multicolumn{5}{|l|}{ HIV testing } \\
\hline \multicolumn{5}{|l|}{ Reason for HIV testing } \\
\hline Regular HIV testing & $432(71.5)$ & $196(73.4)$ & $236(70.0)$ & \multirow[t]{6}{*}{0.011} \\
\hline Had unprotected sexual behavior & $60(9.9)$ & $22(8.2)$ & $38(11.3)$ & \\
\hline Had suspicions symptoms of AIDS & $47(7.8)$ & $19(7.1)$ & $28(8.3)$ & \\
\hline Awareness of HIV testing results before sex & $36(6.0)$ & $10(3.7)$ & $26(7.7)$ & \\
\hline Repeated HIV testing & $29(4.8)$ & $20(7.5)$ & $9(2.7)$ & \\
\hline Missing(Had never HIV testing before) & 95 & & & \\
\hline \multicolumn{5}{|l|}{ Frequency of HIV testing ${ }^{b}$} \\
\hline 0 & $114(16.3)$ & $4(1.5)$ & $110(25.5)$ & \multirow[t]{3}{*}{$<0.001$} \\
\hline 1 & $220(31.5)$ & $76(28.5)$ & $144(33.3)$ & \\
\hline$\geq 2$ & $365(52.2)$ & $187(70.0)$ & $178(41.2)$ & \\
\hline \multicolumn{5}{|l|}{ Time since latest HIV testing (months) } \\
\hline $1 \sim$ & $148(24.5)$ & $81(30.3)$ & $67(19.9)$ & \multirow[t]{5}{*}{0.005} \\
\hline $4 \sim$ & $176(29.1)$ & $77(28.8)$ & $99(29.4)$ & \\
\hline $7 \sim$ & $92(15.2)$ & $29(10.9)$ & $63(18.7)$ & \\
\hline $13 \sim$ & $188(31.1)$ & $80(30.0)$ & $108(32.0)$ & \\
\hline Missing(Had never HIV testing before) & 95 & & & \\
\hline \multicolumn{5}{|l|}{ Site of the latest HIV testing } \\
\hline CDC & $211(34.9)$ & $85(31.8)$ & $126(37.4)$ & \multirow[t]{4}{*}{0.029} \\
\hline Hospital & $43(7.1)$ & $13(4.9)$ & $30(8.9)$ & \\
\hline NGO & $304(50.3)$ & $169(63.3)$ & $181(53.4)$ & \\
\hline Missing (Had never HIV testing before) & 95 & & & \\
\hline
\end{tabular}

a In the prior 6 months

b In the prior one year

c Subgroups were compared using chi-square tests to generate P-

prior 6 months.72.0\% had multiple male sex partners and $27.2 \%$ had unprotected sex with men in the prior 6 months.

\section{Comparisons of characteristics between HIVST users and Non-HIVST users}

Among all participants, 604 (86.4\%) reported having HIV testing at least once in their lifetimes, and 575 (82.3\%) had been tested in the past year. Table 1 describes that a total of 267 participants of $(699,38.2 \%)$ reported having used an HIV self-test kit before, whereas 432 (61.8\%) reported never having HIV self-test. Compared to nonHIVST users, a larger proportion of HIVST users were aged between 18 and 29 years $(58.1 \%$ versus $40.5 \%$, $\mathrm{p}<0.001)$, had college or above education level $(37.8 \%$ versus $29.4 \%, \mathrm{p}=0.022$ ), had lived in Ningbo less than 2 years $(28.5 \%$ versus $18.5 \%, \mathrm{p}=0.002)$, had an income above 5000 China Yuan (CNY) per month $(72.3 \%$ versus $57.2 \%, \mathrm{p}<0.001)$ and self-identified as gay $(82.4 \%$ versus $70.1 \%, \mathrm{p}<0.001)$.

A larger proportion of HIVST users reported having higher frequency of male-male sexual contact $(\geq 1$ time/ week: $53.6 \%$ versus $41.4 \%, \mathrm{p}=0.002$ ), having multiple male sex partners ( $32.6 \%$ versus $25.2 \%, \mathrm{p}=0.035$ ), having had syphilis infection $(10.9 \%$ versus $3.5 \%, \mathrm{p}<0.001)$ and having used gay apps $(88.8 \%$ versus $80.1 \%, \mathrm{p}=0.003)$ in the prior 6 months. Among those who had used gay apps, a greater proportion of HIVST users also had a higher 
frequency of gay apps use ( $\geq 5$ times/day: $63.3 \%$ versus $52.6 \%, \mathrm{p}=0.036)$ in the prior 6 months and used gay apps over 1 year $(89.5 \%$ versus $83.2 \%, \mathrm{p}=0.035)$.

A greater proportion of HIVST users had a higher frequency of HIV testing ( $\geq 2$ times: $70.0 \%$ versus $41.2 \%, \mathrm{p}<0.001)$ in the past 1 year. Among those who had HIV testing before, a greater proportion of HIVST users reported having HIV testing regularly $(73.4 \%$ versus $70.0 \%, \mathrm{p}=0.011$ ), their most recent HIV testing had been within the prior 3 months (30.3\% versus $19.9 \%$, $\mathrm{p}=0.005)$, the site of latest HIV testing was CBO $(63.3 \%$ versus $53.4 \%, \mathrm{p}=0.029$ ).

\section{Factor associated with HIVST uptake}

As show in Table 2, multivariable logistic regression analyses found that the odds of older age (3039 years: $\mathrm{AOR}=0.49$, $\mathrm{CI} 0.32-0.76$; more than 40 years: $\mathrm{AOR}=0.07, \mathrm{CI} 0.04-0.14$, compared to $18-29$ years), bisexual $(\mathrm{AOR}=0.49$, CI $0.29-0.84$ ) were lower among HIVST users,and were higher among MSM who were higher education level (high school: $\mathrm{AOR}=2.82$, CI 1.70-4.69, compared to middle school or less), gay apps use $(\mathrm{AOR}=1.86, \mathrm{CI} 1.13-3.05)$, multiple male sex partners $(\mathrm{AOR}=1.90$, CI 1.29-2.80), frequency of male-male sexual contact $\geq 1$ times per week $(\mathrm{AOR}=1.86, \mathrm{CI} 1.30$ $2.66)$, syphilis infection ( $\mathrm{AOR}=5.48$, CI 2.53-11.88).

\section{Discussion}

Globally, HIV testing had become an important strategy to end the HIV epidemic [20, 21]. HIVST is reliable, safe, and accurate, which can help increase serostatus awareness and ultimately linkage-to-care or prevention services among HIV high-risk populations [22, 23]. The proportion of HIV testing among MSM in the lifetimes and the past year in our analysis was higher than in other studies, but there is a certain distance to reach the first $90 \%$ targets by 2020 [7, 21]. The study revealed that $38.2 \%$ of MSM had used HIVST before in Ningbo, which was lower than the rates reported in studies from other areas $[24,25]$. The reasons for the relatively low HIVST rate in our study could be related to the lack of inventions to promote HIVST by Ningbo CDC. Our study's contribution to investigate factors associated with HIVST and help the government develop targeted strategies to improve HIV testing among MSM in China.

Our study showed that those MSM who were younger or high education levels were more likely to have had HIVST. It is possible that younger MSM had more worries about positive test results [11]. Worldwide, about $32 \%$ of new HIV infections among adults aged 15 years and older have occurred in youth ages $15-24$ years in 2018 [4]. Therefore, HIVST education should be included as a part of comprehensive sexual and reproductive health education for school-age children and teenagers [23].

Gay apps were very popular among MSM in China [19]. HIV prevention through gay apps was widely applied toward reducing high-risk behaviors and promoting HIV testing [26, 27]. Our results showed that HIVST users had a higher frequency of gay apps use than Non-HIVST users in the prior 6 months. As with previous findings, the utility of mobile health interventions can engage MSM in HIVST in Heifei and Shenzhen, China [28, 29], and increase rates of confirmed HIV diagnoses and linkage to clinical care in the UK [30]. It indicated that HIVST kits usage and offer can be conducted as a part of HIV prevention through gay apps to access to more highrisk populations in China.

Furthermore, consistent with findings in other studies [24], those who had high-risk sex behavior, including multiple male sex partners, frequency of male-male sexual contact more than once per week and syphilis infection were more likely to have had HIVST. It is possible that commercial HIVST kits can be easily bought by online shopping platform in China. These high-risk MSM would be willingness to pay for HIVST kits instead of testing in the hospital [24]. But to avoid possible cost barriers, free HIVST kits might be provided to high-risk populations to achieve the increased testing frequency ${ }^{17}$.

This study demonstrated that HIVST users were more like to have a higher frequency of HIV testing and regular HIV testing compared to non-HIVST users. Regular HIV testing enables early identification and treatment of HIV among at-risk MSM [31]. As mentioned, the US CDC recommends MSM to take up HIV testing every 3-6 months if they have additional HIV risk factors [32]. But most of these MSM have no HIV testing routines [33]. So some HIV interventions should be improved to encourage MSM to use HIVST regular after VCT or HIV risk assessment. The results also showed that twothirds of MSM received HIVST kits form CBO in the latest HIV testing. This indicated that $\mathrm{CBO}$ had become an important role in HIV intervention in China. So the government might strengthen support to $\mathrm{CBO}$ to promote HIVST uptake.

\section{Limitations}

The present study had several limitations. First, participants were relatively high-educated, had higher income, and our findings may not be generalizable in other contexts or settings. Second, some questions were asked in the prior 6 months. Despite implemented quality control measures, recall and social desirability bias might have existed.Third, this was not a representative sample of the MSM population in Ningbo, because only those who had a willingness and 
Table 2 Factors associated with HIVST among study participants in Ningbo, China, 2019 ( $n=699)$

\begin{tabular}{|c|c|c|c|c|}
\hline Factor & $\begin{array}{l}\text { Unadjusted } \\
\text { OR }(\mathrm{Cl})^{\mathrm{b}}\end{array}$ & P-value & $\begin{array}{l}\text { Adjusted } \\
\text { OR }(\mathrm{Cl})^{\mathrm{b}}\end{array}$ & P-value \\
\hline \multicolumn{5}{|l|}{ Age (years) } \\
\hline $18 \sim$ & 1.00 & & 1.00 & \\
\hline $30 \sim$ & $0.72(0.51-1.01)$ & 0.054 & $0.49(0.32-0.76)$ & 0.001 \\
\hline$\geq 40$ & $0.20(0.12-0.34)$ & $<0.001$ & $0.07(0.04-0.14)$ & $<0.001$ \\
\hline \multicolumn{5}{|l|}{ Marital status } \\
\hline Married & 1.00 & & - & \\
\hline Single & $1.08(0.78-1.48)$ & 0.653 & - & - \\
\hline \multicolumn{5}{|l|}{ Education level } \\
\hline Middle school or less & 1.00 & & 1.00 & \\
\hline High school & $1.74(1.17-2.57)$ & 0.006 & $2.82(1.70-4.69)$ & $<0.001$ \\
\hline College or above & $1.35(0.92-1.99)$ & 0.123 & $1.42(0.92-2.20)$ & 0.052 \\
\hline \multicolumn{5}{|l|}{ Local residence time } \\
\hline$<2$ & 1.00 & & 1.00 & \\
\hline 2 & $0.57(0.40-0.82)$ & 0.002 & $0.66(0.44-1.00)$ & 0.052 \\
\hline \multicolumn{5}{|l|}{ Monthly income (CNY) } \\
\hline$<5000$ & 1.00 & & 1.00 & \\
\hline$\geq 5000$ & $1.95(1.41-2.71)$ & $<0.001$ & $1.35(0.94-1.93)$ & 0.100 \\
\hline \multicolumn{5}{|l|}{ Sexual orientation } \\
\hline Gay & 1.00 & & 1.00 & \\
\hline Bisexual & $0.46(0.30-0.71)$ & $<0.001$ & $0.49(0.29-0.84)$ & 0.009 \\
\hline Unknown/unsure & $0.64(0.32-1.26)$ & 0.198 & $0.71(0.34-1.51)$ & 0.379 \\
\hline \multicolumn{5}{|l|}{ Gay apps use } \\
\hline No & 1.00 & & 1.00 & \\
\hline Yes & $1.96(1.26-3.07)$ & 0.003 & $1.86(1.13-3.05)$ & 0.014 \\
\hline \multicolumn{5}{|c|}{ Multiple male sex partners ${ }^{a}$} \\
\hline No & 1.00 & & 1.00 & \\
\hline Yes & $1.43(1.02-2.00)$ & 0.036 & $1.90(1.29-2.80)$ & 0.001 \\
\hline \multicolumn{5}{|c|}{ Frequency of male-male sexual contact (times/week) ${ }^{\mathrm{a}}$} \\
\hline$<1$ & 1.00 & & 1.00 & \\
\hline$\geq 1$ & $1.63(1.20-2.22)$ & 0.002 & $1.86(1.30-2.66)$ & 0.001 \\
\hline \multicolumn{5}{|c|}{ Unprotected sex with men ${ }^{a}$} \\
\hline No & 1.00 & & - & \\
\hline Yes & $0.77(0.54-1.09)$ & 0.134 & - & - \\
\hline \multicolumn{5}{|l|}{ Syphilis infection } \\
\hline No & 1.00 & & 1.00 & \\
\hline Yes & $3.39(1.78-6.45)$ & $<0.001$ & $5.48(2.53-11.88)$ & $<0.001$ \\
\hline
\end{tabular}

a In the prior 6 months

${ }^{\text {b }}$ Univariate and multivariate regression analyses were used to generate odds ratios (ORs) and 95\% confidence intervals (Cls)

contacted trained project workers could be recruited into the study.Finally, as this was a cross-sectional study, we are unable to establish a causal relationship.

\section{Conclusions}

The coverage of HIVST had a significant gap in Ningbo, China. It is necessary to make continued efforts to expand HIVST coverage among MSM. Further HIVST education should strengthen for school-age children and teenagers, HIV prevention should include HIVST 
kits usage and offer through gay apps and $\mathrm{CBO}$, and free HIVST kits might be provided to high-risk MSM to accelerate achieve the "90-90-90" goal.

\author{
Abbreviations \\ HIVST: HIV self-testing; PLWH: People are living with HIV; VCT: Voluntary HIV \\ counseling and testing; CDC: Centers for disease control and prevention.
}

\section{Authors' contributions}

$\mathrm{HH}$ and $\mathrm{HS}$ designed the study, $\mathrm{HH}$ and $\mathrm{HD}$ coordinated the study, $\mathrm{HS}$ and $\mathrm{HJ}$ collected the data, $\mathrm{HH}$ did the primary data analysis, $\mathrm{HH}$ and $\mathrm{HS}$ contributed to part of the analysis. $\mathrm{HH}, \mathrm{HS}$, and YS drafted the paper. All authors contributed to results interpretation interpreted the data, revised the article, and approved the final version and manuscript revision. HD and YS had access to all the data and were responsible for the final decision to submit the manuscript for publication. All authors read and approved the final manuscript.

\section{Funding}

This study was supported by the Zhejiang Natural Science Fund (LQ20H260005), the Ningbo Natural Science Fund (2019A610380), Ningbo Health Branding Subject Fund (PPXK2018-10), and Zhejiang Medical Key Discipline (07-013). The funding organizations had no role in the design and conduct of this study.

\section{Availability of data and materials}

The datasets used and/or analyzed during this study is not publicly available, but may be available from the corresponding author upon reasonable request, and with permission from Ningbo Municipal Center for Disease Control and Prevention.

\section{Declarations}

\section{Competing interests}

None declared.

Received: 10 September 2020 Accepted: 8 April 2021

Published online: 20 April 2021

\section{References}

1. UNAIDS. Global AIDS update 2019-Communities at the centre. https:// www.unaids.org/en/resources/documents/2019/2019-global-AIDSupdate. Accessed date 26 Mar 2021.

2. Dong M-J, Peng B, Liu Z-F, Ye Q-N, Liu H, Lu X-L, et al. The prevalence of HIV among MSM in China: a large-scale systematic analysis. BMC Infect Dis. 2019;19:1000

3. Hessou PHS, Glele-Ahanhanzo Y, Adekpedjou R, Ahouada C, Johnson $\mathrm{RC}$, Boko M, et al. Comparison of the prevalence rates of HIV infection between men who have sex with men (MSM) and men in the general population in sub-Saharan Africa: a systematic review and meta-analysis. BMC Public Health. 2019:19:1634.

4. UNAIDS. UNAIDS data. 2019. https://www.unaids.org/en/resources/ documents/2019/2019-UNAIDS-data. Accessed date 31 Dec 2019.

5. UNAIDS. Miles to go_closing gaps, breaking barriers, righting injustices. 2018. https://www.unaids.org/en/resources/documents/2018/globalaids-update. Accessed date 2 Jan 2020.

6. UNAIDS. Fast-Track—Ending the AIDS epidemic by 2030. 2014. https:// www.unaids.org/en/resources/documents/2014/JC2686_WAD2014rep ort. Accessed date 13 Jan 2020.

7. Marsh K, Eaton JW, Mahy M, Sabin K, Autenrieth CS, Wanyeki I, et al. Global, regional and country-level 90-90-90 estimates for 2018: assessing progress towards the 2020 target. AIDS. 2019;33(3):S213-6.

8. Fan L, Fangfang C. National HIV/AIDS epidemic estimation and interpretation in China. Chin J Epidemiol. 2019;40:1191-6.

9. Thapa S, Hannes K, Cargo M, Buve A, Peters S, Dauphin S, et al. Stigma reduction in relation to HIV test uptake in low- and middle-income countries: a realist review. BMC Public Health. 2018:18:1277.
10. Strömdahl S, Hoijer J, Eriksen J. Uptake of peer-led venue-based HIV testing sites in Sweden aimed at men who have sex with men (MSM) and trans persons: a cross-sectional survey. Sex Transm Infect. 2019;95:575-9.

11. Zhou J, Chen J, Goldsamt L, Wang H, Zhang C, Li X. HIV testing and associated factors among men who have sex with men in Changsha. Ch J Assoc Nurses AIDS Care. 2018;29:932-41.

12. World Health Organization. Guidelines on HIV self-testing and partner notification: supplement to consolidated guidelines on HIV testing services. Geneva, Switzerland: WHO, 2016. World Health Organization. http://www.who.int/hiv/pub/self-testing/hiv-self-testing-guidelines/en/. Accessed date 30 Aug 2020.

13. Stevens DR, Vrana CJ, Dlin RE, Korte JE. A global review of hiv self-testing: themes and implications. AIDS Behav. 2018;22:497-512.

14. Harichund C, Moshabela M. Acceptability of HIV Self-testing in SubSaharan Africa: scoping Study. AIDS Behav. 2018;22:560-8.

15. Johnson CC, Kennedy C, Fonner V, Siegfried N, Figueroa C, Dalal S, et al. Examining the effects of HIV self-testing compared to standard HIV testing services: a systematic review and meta-analysis. J Int AIDS Soc 2017;20:21594

16. Harichund C, Kunene P, Moshabela M. Feasibility of HIV self-testing: experiences of people seeking HIV testing in rural and urban KwaZulu-Natal South Africa. Afr J AIDS Res. 2019;18:115-22.

17. Katz DA, Golden MR, Hughes JP, Farquhar C, Stekler JD. HIV Self-testing increases HIV testing frequency in high-risk men who have sex with men: a randomized controlled trial. J Acquir Immune Defic Syndr. 2018;78:505-12.

18. Liu F, Qin Y, Meng S, Zhang W, Tang W, Han L, et al. HIV self-testing among men who have sex with men in China: a qualitative implementation research study. J Virus Erad. 2019;5:220-4.

19. Hong H, Xu J, McGoogan J, Dong H, Xu G, Wu Z. Relationship between the use of gay mobile phone applications and HIV infection among men who have sex with men in Ningbo, China: a cross-sectional study. Int J STD AIDS. 2018;29:491-7.

20. Sharma M, Ying R, Tarr G, Barnabas R. Systematic review and meta-analysis of community and facility-based HIV testing to address linkage to care gaps in sub-Saharan Africa. Nature. 2015;528:S77-85

21. Stannah J, Dale E, Elmes J, Staunton R, Beyrer C, Mitchell KM, et al. HIV testing and engagement with the HIV treatment cascade among men who have sex with men in Africa: a systematic review and meta-analysis. Lancet HIV. 2019;6:e769-87.

22. Pittalis S, Orchi N, De Carli G, Navarra A, Chiaradia G, Puro V, et al. HIV SelfTesting in Italy. J Acquir Immune Defic Syndr. 2017;76:e84-5.

23. Kojima N, Klausner JD. Accelerating epidemic control: the role of HIV selftesting. Lancet HIV. 2018;5:e266-7.

24. Ren XL, Wu ZY, Mi GD, McGoogan J, Rou KM, Zhao Y. Uptake of HIV Selftesting among men who have sex with men in Beijing, China: a crosssectional study. Biomed Environ Sci. 2017;30:407-17.

25. Tun W, Vu L, Dirisu O, Sekoni A, Shoyemi E, Njab J, et al. Uptake of HIV selftesting and linkage to treatment among men who have sex with men (MSM) in Nigeria: a pilot programme using key opinion leaders to reach MSM. J Int AIDS Soc. 2018;21:e25124.

26. Yan J, Zhang A, Zhou L, Huang Z, Zhang P, Yang G. Development and effectiveness of a mobile phone application conducting health behavioral intervention among men who have sex with men, a randomized controlled trial: study protocol. BMC Public Health. 2017;17:355.

27. SESH Study Group, Tucker JD. Crowdsourcing to promote HIV testing among MSM in China: study protocol for a stepped wedge randomized controlled trial. Trial. 2017;18:447.

28. Zhao Y, Zhu X, Pérez AE, Zhang W, Shi A, Zhang Z, et al. MHealth approach to promote Oral HIV self-testing among men who have sex with men in China: a qualitative description. BMC Public Health. 2018;18:1146.

29. Zhu X, Zhang W, Operario D, Zhao Y, Shi A, Zhang Z, et al. Effects of a Mobile Health Intervention to Promote HIV Self-testing with MSM in China: a randomized controlled trial. AIDS Behav. 2019;23:3129-39.

30. Gabriel MM, Dunn DT, Speakman A, McCabe L, Ward D, Witzel TC, et al. Protocol, rationale and design of SELPHI: a randomised controlled trial assessing whether offering free HIV self-testing kits via the internet increases the rate of HIV diagnosis. BMC Infect Dis. 2018;18:1-0.

31. Noble M, Jones AM, Bowles K, DiNenno EA, Tregear SJ. HIV testing among internet-using MSM in the United States: systematic review. AIDS Behav. 2017;21:561-75. 
32. DiNenno EA, Prejean J, Irwin K, Delaney KP, Bowles K, Martin T, et al. Recommendations for HIV screening of gay, bisexual, and other men who have sex with men-United States, 2017. MMWR Morb Mortal Wkly Rep. 2017;66:830-2.

33. Adam PCG, de Wit JBF, Bourne CP, Knox D, Purchas J. Promoting regular testing: an examination of HIV and STI testing routines and associated socio-demographic, behavioral and social-cognitive factors among men who have sex with men in New South Wales. Australia AIDS Behav. 2014;18:921-32.

\section{Publisher's Note}

Springer Nature remains neutral with regard to jurisdictional claims in published maps and institutional affiliations.
Ready to submit your research? Choose BMC and benefit from:

- fast, convenient online submission

- thorough peer review by experienced researchers in your field

- rapid publication on acceptance

- support for research data, including large and complex data types

- gold Open Access which fosters wider collaboration and increased citations

- maximum visibility for your research: over $100 \mathrm{M}$ website views per year

At BMC, research is always in progress.

Learn more biomedcentral.com/submissions 